\title{
Synthesis and thermal study of dual coordination compound of gadolinium (III) and chromium (III)
}

\author{
A. Bobrovnikova, ${ }^{1, a}$, T. Cherkasova ${ }^{1, b}$, A. Shirokolobova ${ }^{1, c}$, A. Syskina ${ }^{2 d}$ \\ ${ }^{1}$ T.F. Gorbachev Kuzbass State Technical University, Kemerovo, Russia \\ ${ }^{2}$ National Research Tomsk Polytechnic University, Tomsk, Russia \\ abobrownickowa.al@yandex.ru, ${ }^{\text {b }}$ ctg.htnv@kuzstu.ru, ${ }^{c}$ nastja_shirokolo@rambler.ru, \\ dannesyskina@yahoo.com
}

\begin{abstract}
The paper presents experimental data of thermal studies of coordination compound based on gadolinium nitrate with the DSCmethod; the study was performed in the temperature range from 298 to $1273 \mathrm{C}$. The thermal analysis has several advantages over the other methods: experimental set up flexibility, fast data receive, automatic data processing, small substance amount. The process of thermal decomposition of the received compound was carried out in both inert and oxidizing environments. During the experiment the temperature was defined, above which heating causes decomposition of the investigated substance and weight loss of the sample.
\end{abstract}

\section{Introduction}

In modern industry the development of energy - and resource efficient technologies, such as nuclear power engineering industry, space systems, advanced medical equipment and weapons, military and special equipment, and other trends in the development of science are practically impossible without the use of rare earth metals and their compounds. Even small amounts of these substances in industrial production allow producing technical products, unique in properties and quality, and their derivatives [1].

Gadolinium compounds are intensively used in a number of existing and innovative areas of production, they are used for image visualization in medicine, for optical recording, in glass and ceramics production, in laser technology Gadolinium compounds are included in crystal scintillators and magnets, which are very demanded in advanced technology production [2].

Gadolinium opens a subgroup of heavy lanthanides and has a half-filled f-shell, which has high energy stability. For this reason, the gadolinium ions, unlike some other lanthanides, are always trivalent $\mathrm{Gd}^{+3}$. Gadolinium contains the so-called "gadolinium break", the violation of the monotonic change of properties of lanthanide compounds according to the atomic number.

At present, the Cambridge structural database contains more than 2,000 (2537) crystal compounds with gadolinium as a complex former, among them only one substance has hexamethylphosphorotriamide (HMPA) in its composition [3] (Fig. 1.). A small number of structurally characterized compounds with Gd and HMPA, available in the Cambridge structural database, indirectly indicates the lack of study on hexamethylphosphorotriamide complex formation. 
Previously [4-6], ammonium tetra(isothiocynato)diaminechromate(III) hemihydrade (Reinecke's salt) was used as a ligand. The compounds with gadolinium (III), Reinecke's salt, and HMPA were not found in the structure.

The purpose of this paper is thermal study of synthesized thiocyanate complex based on gadolinium and hexamethylphosphorotriamide in a wide temperature range via the method of differential scanning calorimetry (DSC).

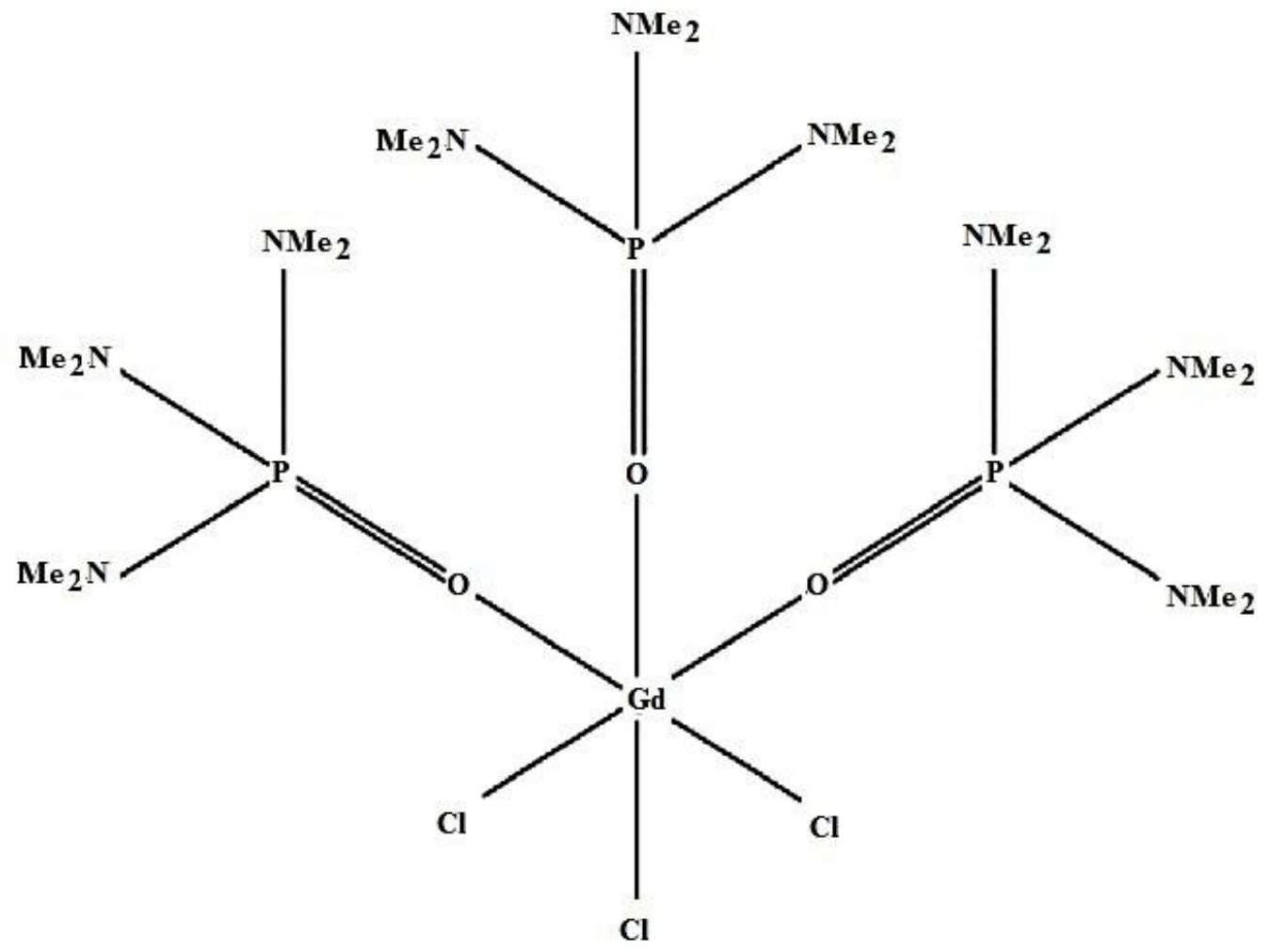

Figure 1. Complex structure fac-[ $\left.\mathrm{GdCl}_{3}(\mathrm{HMPA})_{3}\right]$

This method is used as a type of thermal analysis in the study of thermal properties of substances. Combined DSC-TG analysis (i.e. registration of thermal effects with simultaneous current change of weight of the sample) allows controlling the processes of dehydration, removing volatile compounds, as well as binder burnout. The obtained data make it possible to determine the enthalpy of phase transitions with exact reference to the temperatures of reactions [7-10].

\section{Experiment}

Ammonoium

tetra(isothiocynato)diaminechromate(III)

hemihydrates

$\mathrm{NH}_{4}\left[\mathrm{Cr}\left(\mathrm{NH}_{3}\right)_{2}(\mathrm{NCS})_{4}\right] \bullet 0,5 \mathrm{H}_{2} \mathrm{O}$, hexamethylphosphorotriamide $\left(\left(\mathrm{CH}_{3}\right)_{2} \mathrm{~N}\right)_{3} \mathrm{PO}$ and $\mathrm{Gd}\left(\mathrm{NO}_{3}\right)_{3} \cdot \mathrm{H}_{2} \mathrm{O}$ line «C.P.» are chosen as initial substances for synthesis of coordinate substances.

While mixing aqueous solutions of gadolinium nitrate and Reinecke's salt, in molecular ratio 1:1, with later dropwise addition of organic ligand - HMPA, at $\mathrm{pH}$ 6-7 and the solution concentration is 0.05-0.5 mole/1 fine-crystalline precipitates settle out, the composition $\left[\mathrm{Gd}(\mathrm{HMPA})_{4}\left(\mathrm{NO}_{3}\right)_{2}\right]\left[\mathrm{Cr}\left(\mathrm{NH}_{3}\right)_{2}(\mathrm{NCS})_{4}\right](\mathrm{I})$.

To carry out the synchronous thermal analysis, NETZSCH STA 449 C Jupiter analyzer was used, it allows simultaneous registration of thermogravimetry (TG) and differential scanning calorimetry 
(DSC) curves under programmable non-isothermal heating conditions, with the standard $\alpha-\mathrm{Al}_{2} \mathrm{O}_{3}$ at the heating rate of $10 \mathrm{~K} / \mathrm{min}$ in the temperature range from 298 to $1273 \mathrm{~K}$.

The results of the study on the thermal behavior of the complex in air are shown in Fig. 2, in an inert atmosphere - in Fig. 3.

\section{Results and discussion}

The present study is a continuation of the thermolysis processes research in air and in an inert atmosphere of double complex compounds (DCC) with cations - lanthanide complexes with neutral organic ligands and inert complex rhodanate anions of chromium (III); the research is devoted to the study of thermal decomposition processes of a new compound.

Thermogram analysis shows that the complex compound is thermally stable up to the temperature of $385 \mathrm{~K}$. Ammonia molecules split off and burn, and the molecules of HMPA remove when it is over $385 \mathrm{~K}$ (in the temperature range from 385 to $413 \mathrm{~K}$ ).

The main weight loss occurs in the range from 473 to $873 \mathrm{~K}$ (Fig. 2). In the DSC curve, the discussed range is presented by a number of exoeffects with extremes caused by sample decomposition and decomposition products combustion.

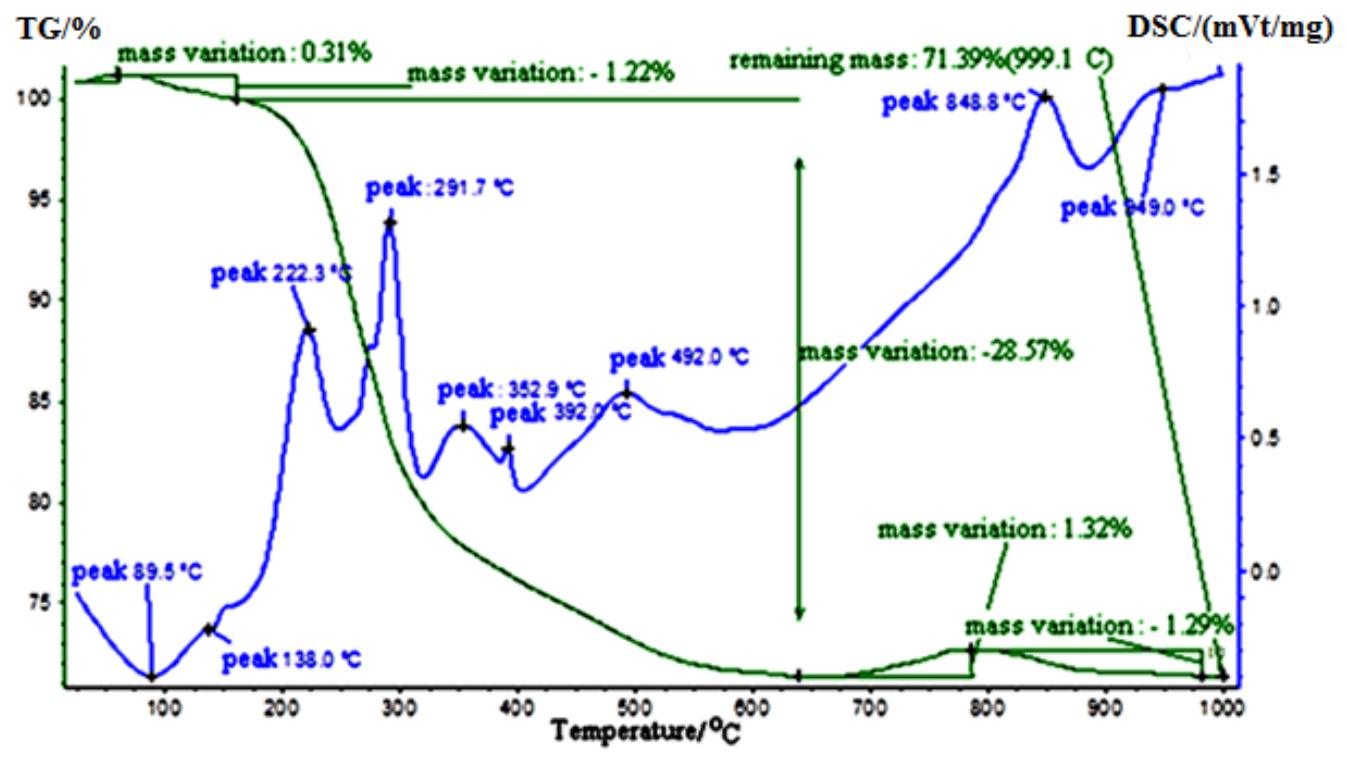

Figure 2. The thermogram of the compound composition $\left.\mathrm{Gd}(\mathrm{HMPA})_{4}\left(\mathrm{NO}_{3}\right)_{2}\right]\left[\mathrm{Cr}\left(\mathrm{NH}_{3}\right)_{2}(\mathrm{NCS})_{4}\right]$ in air

The DSC curve of the sample I shown in Fig. 2 demonstrates six expressed thermal effects: the first two are endothermic effects starting at 363 and $433 \mathrm{~K}$, the following two are exothermic effects starting at 483 and $533 \mathrm{~K}$, they are followed by endoeffect at $583 \mathrm{~K}$ and exoeffect at $713 \mathrm{~K}$. Exothermic effects correspond to a significant loss of the sample weight.

To interpret the processes of thermal decomposition of the obtained complex in inert argon atmosphere, the curves of thermal decomposition of HMPA and Reinecke salt were taken.

The thermolysis processes $\mathrm{NH}_{4}\left[\mathrm{Cr}\left(\mathrm{NH}_{3}\right)_{2}(\mathrm{NCS})_{4}\right] \cdot 0,5 \mathrm{H}_{2} \mathrm{O}$ are characterized by a number of effects. In the temperature range from 340 to $353 \mathrm{~K}$ there is a gradual removal of one water molecule and ammonium cation; the sample weight loss is $10.10 \%$. Then the decomposition of the anionic part of the complex begins (the sample weight loss is $43.55 \%$ at a maximum rate). Three endoeffects were 
recorded at the temperature of $461,544,581 \mathrm{~K}$ corresponding to the removal of two ammonia molecules and two isothiocyanate ligands.

To confirm the correctness of the thermolysis process interpretation, the IR spectra of the solid decomposition products of the complex I were taken.

There are no absorption bands of the valence vibrations of ammonia $\mathrm{NH}$-groups $(v(\mathrm{NH})=3366$, $\left.3310,3165 \mathrm{~cm}^{-1}\right)$, and the main absorption bands of isothiocyanate groups $(v(\mathrm{CN}), v(\mathrm{CS}), \delta(\mathrm{NCS}))$ and group P-O remain in the IR spectrum of the decomposition product I at the temperature of $473 \mathrm{~K}$. The decomposition of HMPA molecules and anionic parts of the complex $(\Delta \mathrm{m}=28.46 \%)$ can be seen in the temperature range from 490 to $715 \mathrm{~K}$. There are no major absorption bands of isothiocyanate groups in the IR spectrum of the decomposition product I at the temperature $673 \mathrm{~K}$.

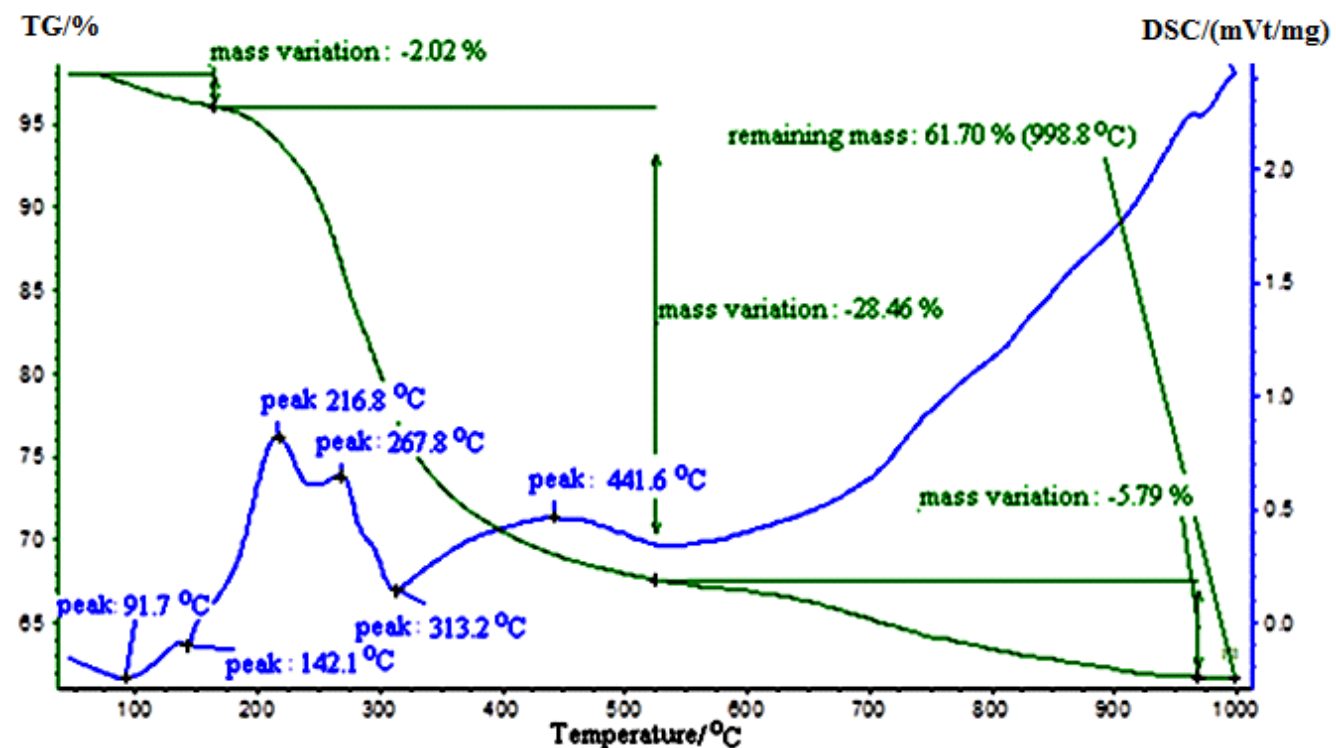

Figure 3. The thermogram of the compound composition $\left[\mathrm{Gd}(\mathrm{HMPA})_{4}\left(\mathrm{NO}_{3}\right)_{2}\right]\left[\mathrm{Cr}\left(\mathrm{NH}_{3}\right)_{2}(\mathrm{NCS})_{4}\right]$ in argon atmosphere

Thus, the behaviour modes of samples in air and argon atmosphere are similar (Fig. 4).

The data of the sample weight loss make it possible to determine the number of HMPA moles per formula unit of the compound (about 2 moles). 


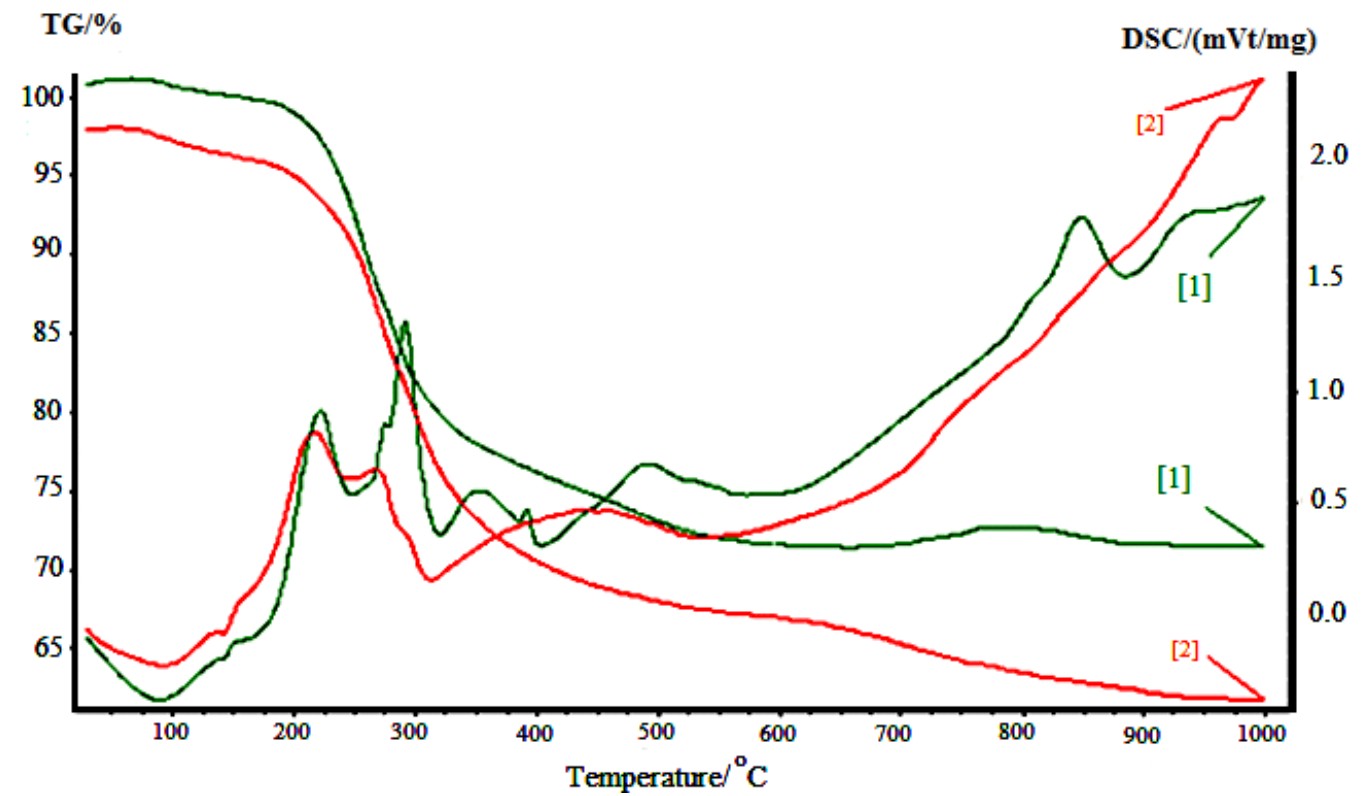

Figure 4. The thermogram of the compound composition $\left[\mathrm{Gd}(\mathrm{HMPA})_{4}\left(\mathrm{NO}_{3}\right)_{2}\right]\left[\mathrm{Cr}\left(\mathrm{NH}_{3}\right)_{2}(\mathrm{NCS})_{4}\right]: 1$ - study in air, 2 - study in argon atmosphere

The double complex compound is less stable to heat due to the presence of organic molecules, as well as the coordinated ammonia in the anions of Reinecke salt. The ligands nature influences the thermal behavior of substances.

\section{Conclusion}

The technique to obtain a new dual complex compound of gadolinium (III) with Reinecke salt and hexamethylphosphorictriamide was developed.

The application of modern simultaneous thermal analysis allowed studying the behavior of the new compoundwith high accuracy at low sample consumption. The thermolysis process of the sample is complex and multistageous. The main part of the organic component is removed in the temperature range from 473 to $873 \mathrm{C}$.

The coordination compound with the inert anion of chromium (III) is suitable for obtaining the mixed oxide systems by thermal decomposition of the double complex compound in air at relatively low temperatures.

The work was performed within the project of the Ministry of Education of Russia (project number $10.782 .2014 \mathrm{~K})$.

\section{References}

[1] Pavlishchuk A, Kolotilov S, Zeller M, Thompson L and Addison A 2014 Inorganic Chemistry 533 pp 1320-1330

[2] Babailov S, Chuikov I and Kruppa A 2016 Inorganica Chimica Acta 439 pp 117-122

[3] Gavriluta A, Tommasino J, Iasco O, Druta V, Luneau D, Kuhn P, Arion V, Claiser N and Novitchi G 2015 European Journal of Inorganic Chemistry 9 pp 1616-1624

[4] Cherkasova T, Tatarinova E, Cherkasova E 2014 Polzunovskiy Bulletin 3 pp 98-101

[5] Isakova I, Cherkasova T, Peresypkina E and others 2012 Russian Journal of Inorganic Chemistry 579 pp 1221-1226 
[6] Cherkasova E, Cherkasova T, Peresypkina E and Virovets A 2015 Russian Journal of Inorganic Chemistry 604 pp 493-499

[7] Bobrovnikova A, Cherkasova T, Shirokolobova A and Bolsunovskaia L 2014 Procedia Chemistry [Electronic resource] - Mode of access: http://www.sciencedirect.com/science/article/pii/S1876619614001351 10 pp 530-534

[8] El-Shenawy A, Atta A and Refat M 2014 International Journal of Electrochemical Science 9 pp 5187-5203

[9] Molero-Sánchez B, Chen M, Birss V, Prado-Gonjal J, Ávila-Brande D and Morán E 2015 International Journal of Hydrogen Energy 404 pp 1902-1910

[10] Zhai Y, Huang Z, Zhong Z and Coombs TA 2015 IEEE Transactions on Applied Superconductivity 253 pp 697-505 